تحديد مناطق تغذية المياه الجوفية بالمنطقة فيما بين إدفو وأسوان - مصر، باستخدام نمذجة

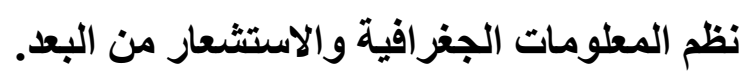

$$
\text { كريم حامد عبد اللطيف }
$$

(طالب دكتور اه) كلية البنات للآداب و العلوم والتربية جامعة عين شمس

$$
\text { أ.د/ سهام محمد هاشم }
$$

(أستاذ الجغر افبا) كلية البنات للآداب و العلوم و التربية جامعة عين شمس

$$
\text { د/ نورة عبد التواب السيد }
$$

(مدرس الجغر افيا) كلية البنات للآداب و العلوم و التربية جامعة عين شمس 


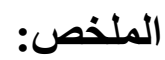

تمثل المياه الجوفية أحدي أهم مصادر المياه العذبة خاصة بالأقاليم الجافة وشبه الجافة، وقد تزايدت أهميتها في الآونة الأخيرة؛ وذلك كنتيجة طبيعية للزيادة السكانية وتز ايد الحاجة الى توافر الفراه

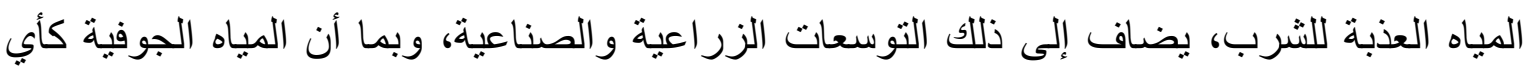
ثروة طبيعية قابلة للنفاد أو النضوب، لذا كان لابد من الاهتمام بدراستها لتقدير كمياتها ونوعيتها،

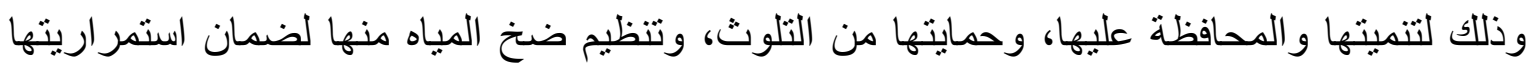
للأجيال القادمة. ويهذف هذا البحث إلى الاستفادة من التكاملية بين نظم المعلومات الجغرافية

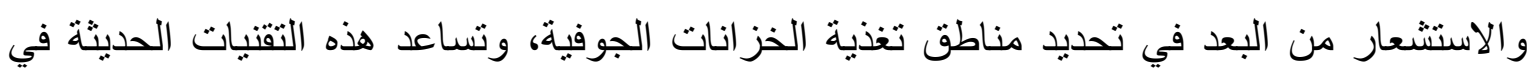
تحديد المناطق الأكثر في التغذية عن مثيلتها، وبالتالي تحديد المناطق الأمثل في إقامة الآبار و التني تتميز باستدامة مياهها. الكلمات الدالة: المياه الجوفية، النمذجة، الاستشعار من البعد، نظم المعلومات الجغر افية. 
تعد المباه أحد أهم العناصر الضرورية للحياة على كوكب الأرض، وقد قال الله تعالي (وَجَعَلْنَا مِنَ

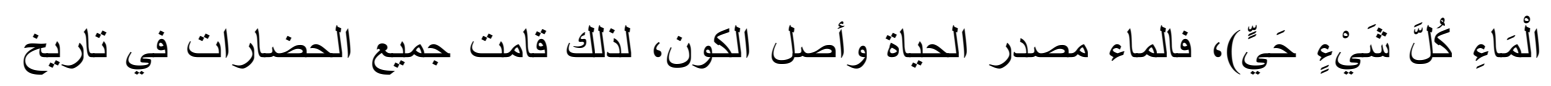

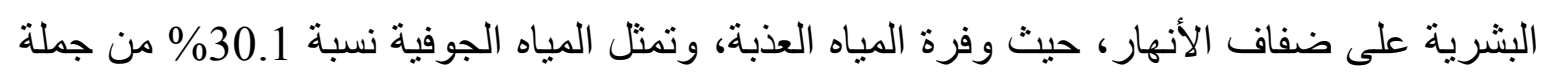
المياه العذبة(1)، وهي نسبة كبيرة تدل على أهميتها كمصدر للمياه العذبة، وتزداد أهميتها في الأقاليم الجافة وشبه الجافة. وقد شهدت الفترة الأخيرة من القرن العشرين تزايداً واضحاً في استعمالات المياه الهياه الجوفية بمنطقة الدراسة، وذلك كنتيجة طبيعية للزيادة السكانية المرتفعة وزيادة الحاجه إلى المياه

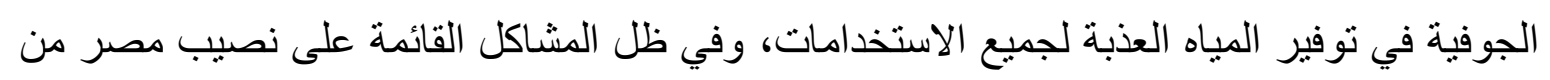
مياه نهر النيل، والتي أصبحت من الصعب زياه زيادتها بما يكفي لمواجهة منطلبات التنمية والزيادة

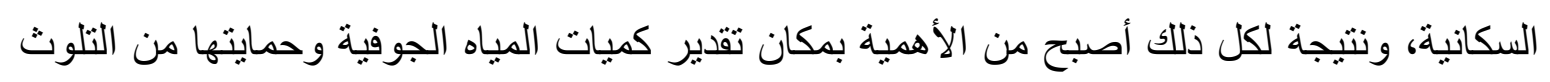
وتنظيم ضخ المياه منها لضمان استمر اريتها كمصدر هام وطبيعي للمياه العذبة.

\section{منطقة الاراسة:}

تقع منطقة الدراسة ضمن الجزء الجنوبي من مصر، وتقع إدارياً بمحافظة أسوان، حيث تمند من

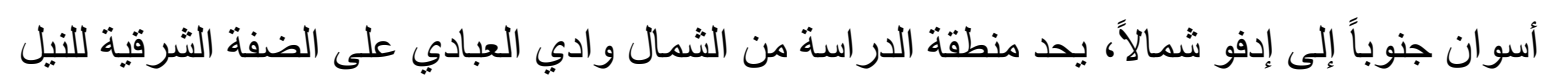

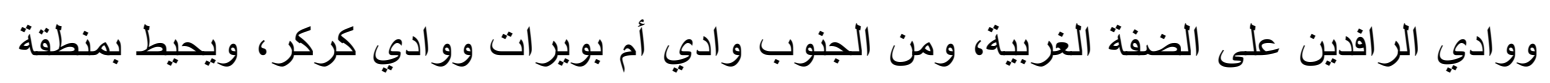

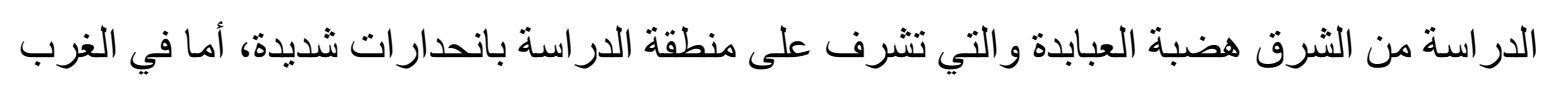

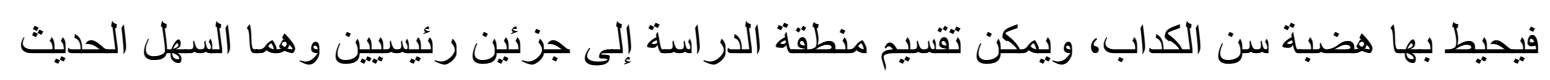
و المتمثل في السهل الفيضي للنيل، والذي يحده خط كنتور 110 منراً فوق سطح البحر، و والسهول

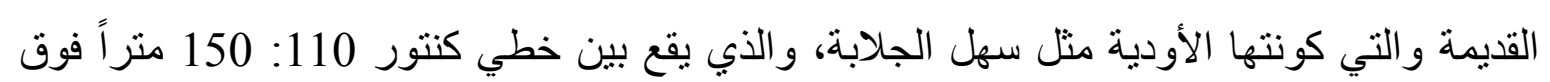

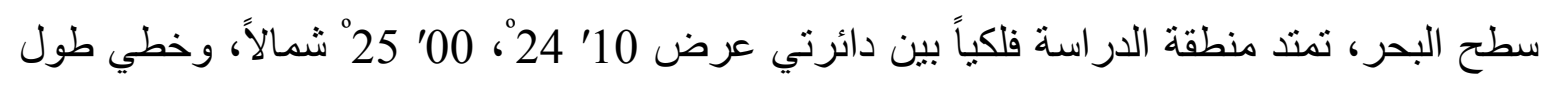

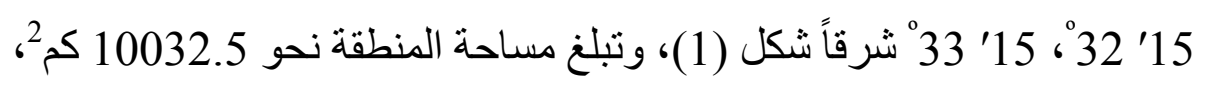
تقع منطقة الدراسة ضمن الأقليم الجاف، حيث تتميز بارتفاع درجة الحرارة على مدار العام حيث

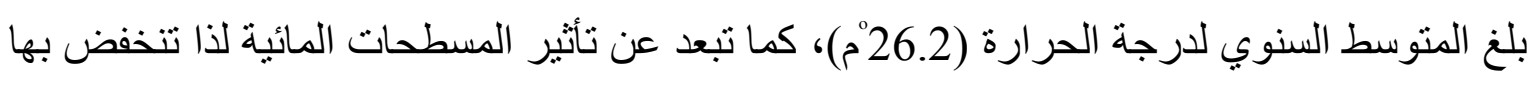
معدلات الرطوبة النسبية بها، حيث تقل عن 50\% في معظم شهور السنة، مما أدي إلى ارتفاع

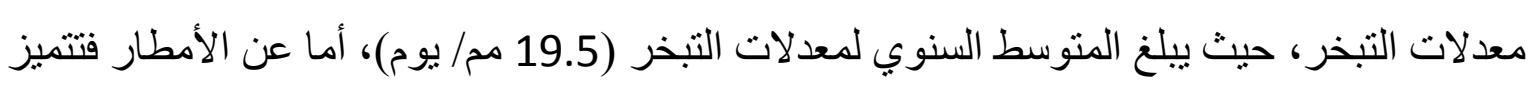

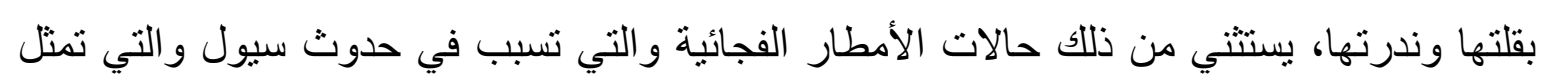
ظاهرة متكررة، أما عن الرياح فتهب من جميع الاتجاهات وهي رياح جالفة الأفي في معظمها. 
شكل (1) موقع منطقة الدر اسة.

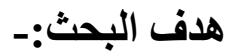

يهذف هذا البحث إلى الاستفادة من التكاملية بين نظم المعلومات الجغر افية والاستشعار من البعد في تحديد مناطق تغذية الخزانات الجوفية بالمياه، وذلك من خلال إنشاء نموذج (Model) في بيئة نظم المعلومات الجغر افية يقوم على العناصر المؤثرة في عملية تغذية الخزانات الجوفية بمنطقة الدراسة، ويوضح الثكل (2) طريقة بناء نموذج تغذية الخزانات الجوفية، حيث تمر مرحلة بناء النموذج بعدد من المر احل و هي كالتالي:-

شكل (2) نموذج لإنتاج خريطة توزيعات مناطق التغذية بمنطقة الدراسة.

1. - إنثاء قاعدة البيانات الجغرافية:

يضم النموذج الذي تم بناءه على عدد من الطبقات تمثل العوامل المختلفة والتي تؤثر في تغذية الخز انات الجوفية بمنطقة الدراسة، ومن أجل سهولة إدارة ومعالجة هذه البيانات و الطبقات المختلفة، نم إنثاء قاعدة بيانات جغرافية (GIS Database)، لتضم جميع هذه العوامل، و هذه العوامل

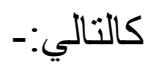

\section{أ- يولوجية منطقة الدراسة:}

تعد جيولوجية المنطقة هي الركيزة الأساسية عند بناء نماذج المياه الجوفية، فمن خلالها يمكن تحديد التكوينات الجيولوجية السطحية وتحت السطحية الحاملة للمياه الجوفية، كما تساعد في تحديد كمية المياه التي يمكن أن تكتسبها الخزانات الجوفية(2)، كما تساعد في التعرف على خصائص المياه

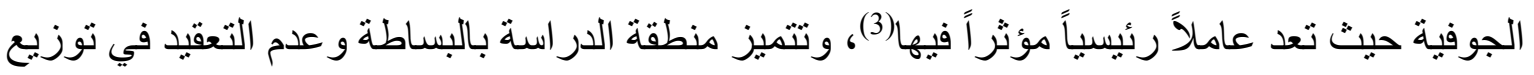
تكويناتها الجيولوجية شكل (2)، وتغطى تكوينات الزمن الرباعي مساحة 37.8\% من مساحة منطقة

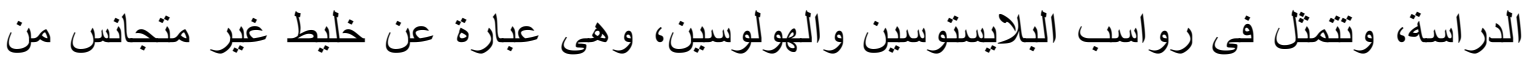

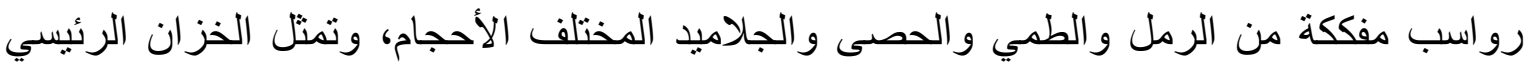

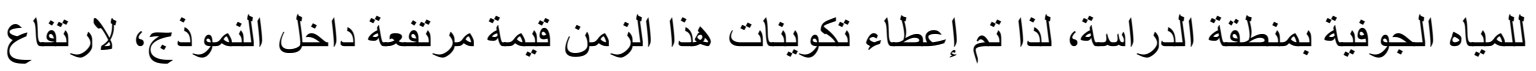

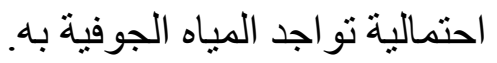


كما تغطى تكوينات الزمن الثاني والمنمثل في تكوينات العصر الطبانشيري العلوي مساحة

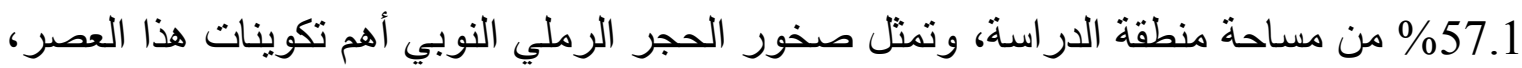
حيث يشغل مساحة 25.4\% من جملة مساحة المنطقة، بل يزيد عن ذلك حيث له امتدادات واسعة

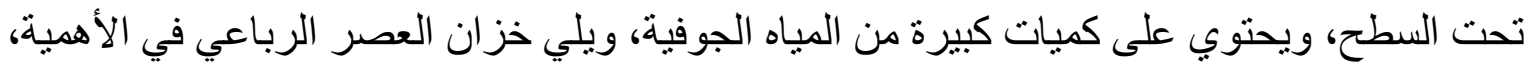
لذا تم إعطاءه قيم أقل من تكوينات الزمن الرباعي داخل النموذج. في حين تغطي تكوينات الزمن

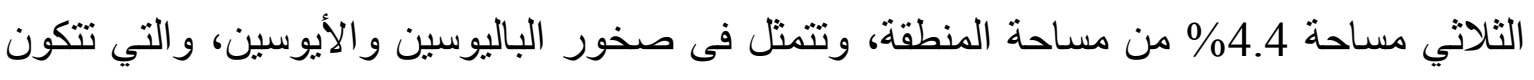

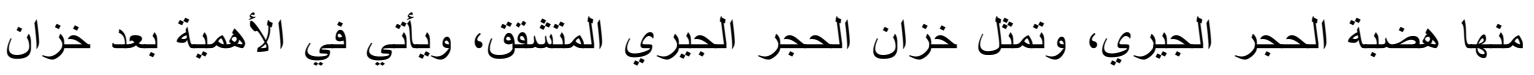

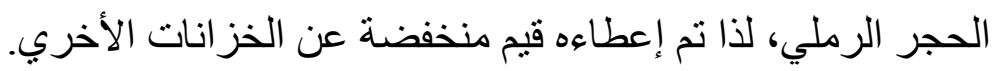

بـ نموذج الارتفاعات الرقمية (Digital Elevation Model): يعد نموذج الارتفاعات الرقمية (DEM) من العو امل المؤثرة في تغذية الخزانات الجوفية، حيث

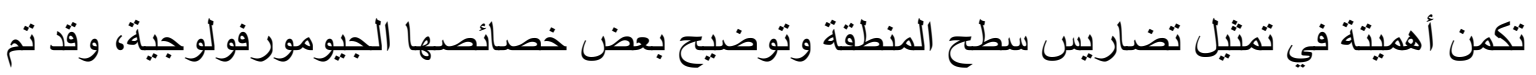

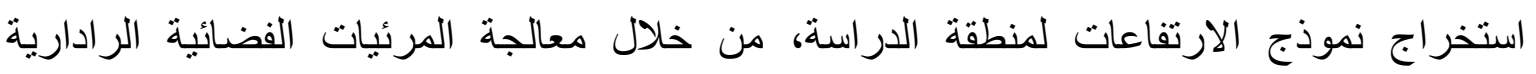
(Shuttle Radar Topography Mission ) متر أ(4)، وقد تم تصنيف نموذج الارتفاعات إلى فئات ارتفاعية شكل (4)، بحيث تمثل كل فئة ظاهرة

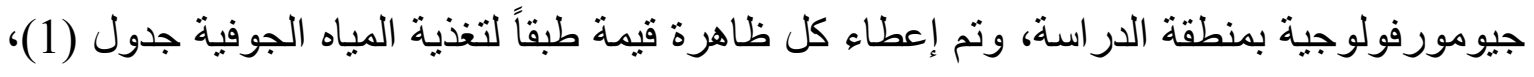
حيث تمثل الفئة (110 متراً فأقل) السهل الفيضي بمنطقة الدراسة وهو يعد من أفضل المناطق تغذيةً

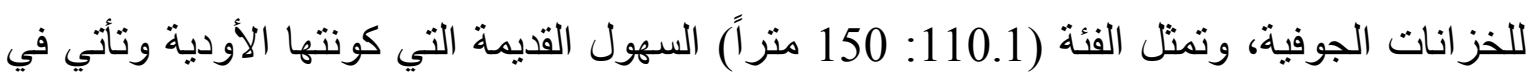
الأهمية بعد الفئة السابق، وتمثل الفئة (150.1 : 190 منراً) مناطق البيدمينت، أما باقي الفئات فتمثل

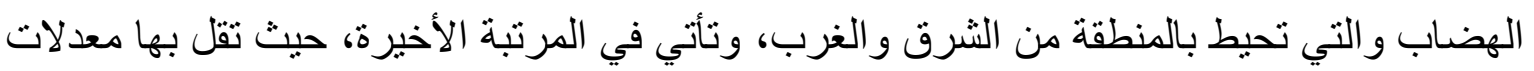
التغذية مقارنة بالفئات الأخري.

شكل (4) نموذج الارتفاعات الرقمية لمنطقة الدراسة.

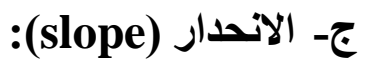
يعد الانحدار من العوامل المهمة والتي تؤثر في تغذية الخزانات الجوفية(5)، حيث نوجد علاقة

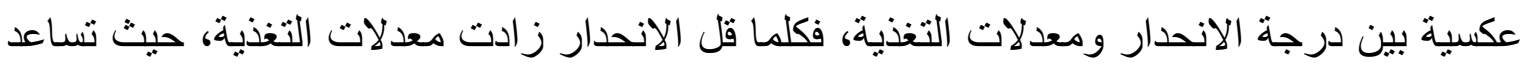
الانحدارات الخفيفة والمعتدلة بانخفاض معدلات الجريان السطحي، مما يعطي مزيد من الوقت للمياه

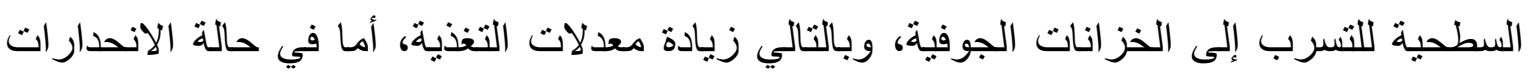

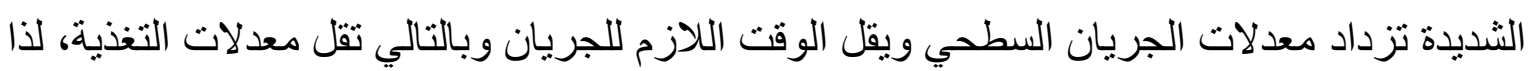


تم إعطاء الانحدارات الثديدة أهمية منخفضة، في حين تم إعطاء أهمية مرتفعة للانحدارات القليلة،

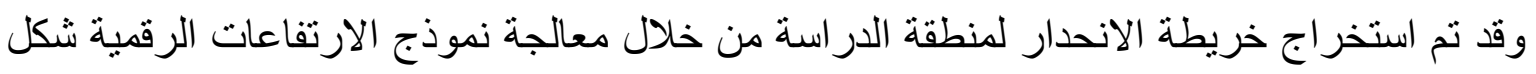

$$
\text { شكل (5) الانحدار ات بمنطقة الدراسة. }
$$

دــ شبكة الترع والمصارف:

تضيف شبكة الترع والمصارف كميات وفيرة من المياه إلى الخزانات الجوفية بمايتسرب منها

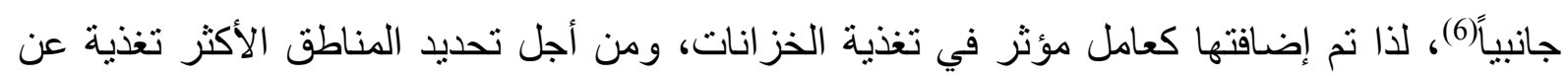

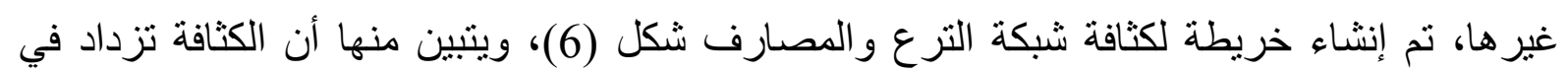

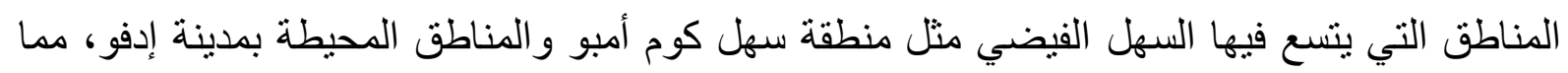
بدل على زيادة معدلات التغذية بمناطق الزر اعات بالسهل الفيضي، كما تزداد الكثافة بمنطقة سهل النقرة

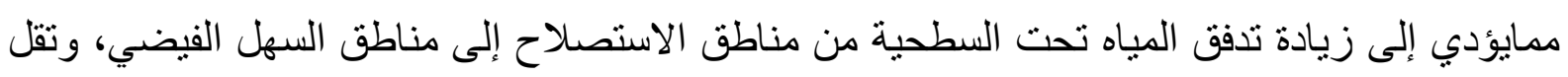

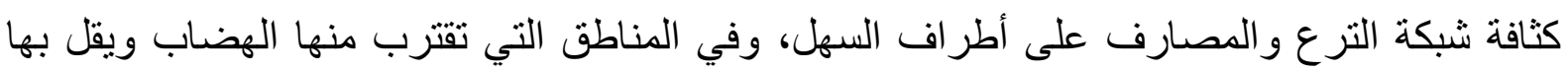

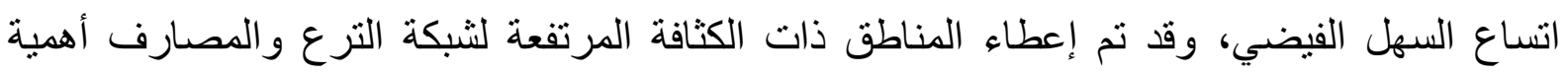

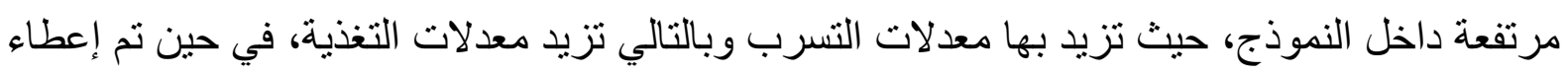
أهية منخفضة للمناطق الكثافة المنخفضة.

شكل (6) نوزيع كثافة شبكة الترع و المصارف الزر اعية بمنطقة الدراسة.

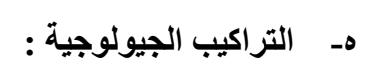

تضم هذه الطبقة كل الظاهر ات الخطية و التي احثثها العمليات الجيولوجية و الجيومورفولوجية، و التي تتمثل في الصدوع السطحية وتحت السطحية والطيات و التشققات و الحافات و غيرها، وتعد هذه الطبقة

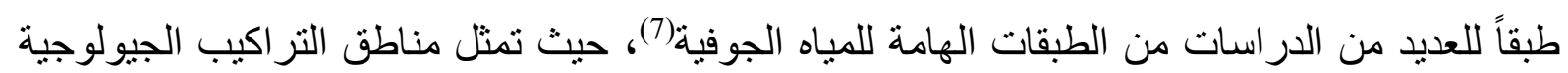
مناطق تغذية جيدة للمياه الجوفية، وقد استخرجت هذ الطبقة من معالجة المرئيات الفضائية لاندسات 8 و المرئيات الر ادارية (SRTM) باستخدام برنامج (PCI Geomatics 2017)، ثم تم استنباط خريطة

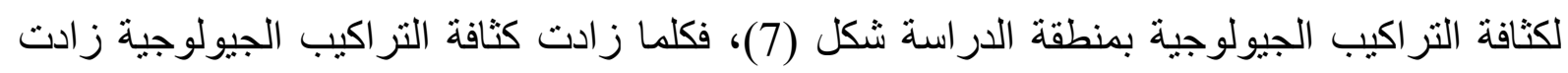
كميات المياه المنسرب إلى الخزانات الجوفية، لذا نم إعطاء أهمية مرتفعة للمناطق ذات كثافة التر اكيب لهيب الجيولوجية المرتفعة، في حين تم إعطاء قيم منخفضة للمناطق ذات الكثافة المنخفضة. 
شكل (7) كثافة التر اكيب الجيولوجية بمنطقة الدراسة.

وـ شبكة التصريف النهري وكثافتها:

تشمل هذه الطبقة شبكة التصريف النهري وكثافتها، وتكتسب هذه الطبقة أهيتها من أنها تعطي معلومات عن طبو غر افية المنطقة والسطح ومعدلات الجريان السطحي و والتسرب و النفاذية(8)، فالكثافة المرتفعة لثبكة التصريف تحدث في المناطق التي تكون بها طبيعة الصخور منخفضة النفاذية، وبذلك تتخفض بها معدلات التسرب، وبالتالي تقل المياه التي تصل إلى الخزانات الجوفية، لذا تعد مناطق الكثافة لهن

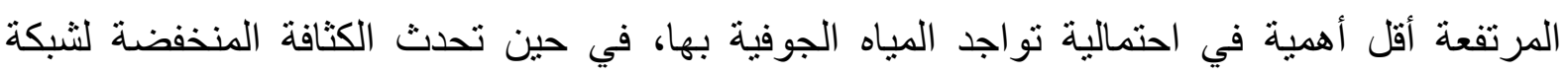

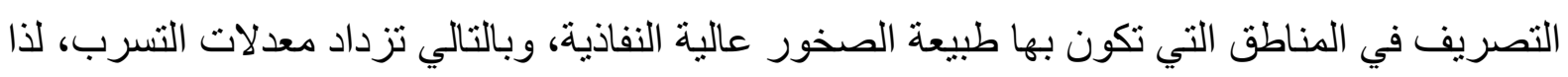
يحدث تغذية أعلي للخز انات الجوفية، لذا تعد من أفضل مو اقع المحتملة للمباه الجوفية. وقد تم استخر اج شبكة التصريف لمنطقة الدر اسة من معالجة المرئيات الفضائية (SRTM)، ومنها ثم نم استخر اج كثافة شبكة التصريف شكل (8)، ومنها يتضح أن هناك تباين في كثافة شبكة التصريف

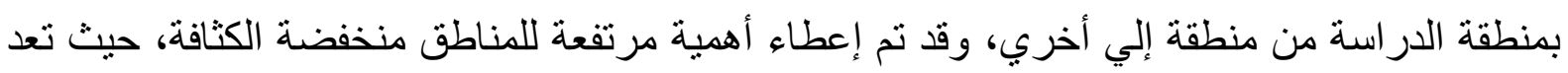

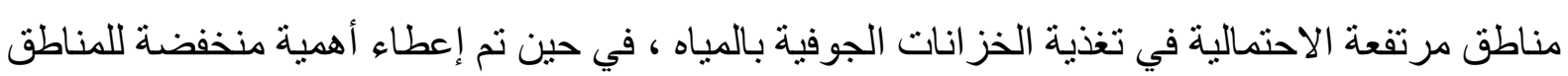
مرتفعة الكثافة، حيث تقل معدلات التغذية بها.

شكل (8) كثافة شبكة التصريف النهري بمنطقة الدر اسة.

ز- استخدامات الأراضي (Land use map):

تعد هذه الطبقة من الطبقات المهمة و التي تؤثر في تغذية الخزانات الجوفية، حيث تؤثر هذه الطبقة في

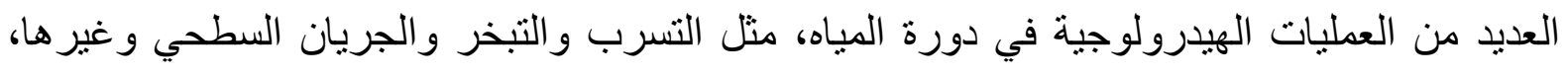

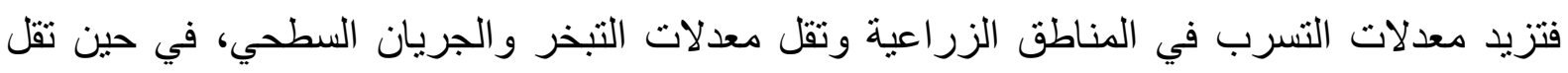

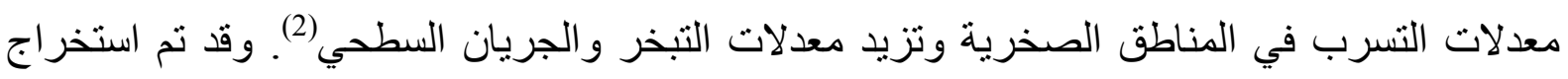

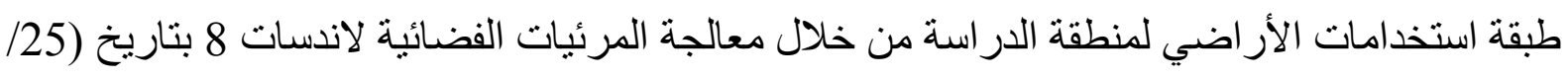

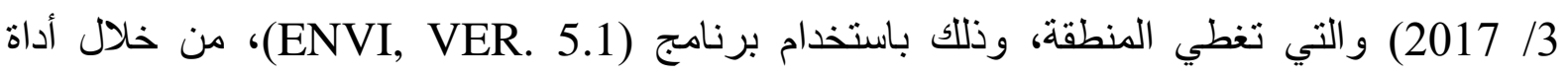

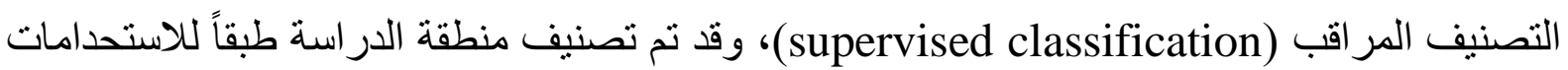
الأر اضي بها شكل (9) إلى مايلي: 
المسطحات المائية: تشمل نهر النيل والبرك وغير ها، وتغطي مساحة 84.9 كم²، أي بنسبة 0.8\% من جملة مساحة منطقة الدراسة، وتمثل هذه المسطحات مناطق تغذية للخز انات الجوفية

$$
\text { القريب منها. }
$$

الأراضي الزراعية: تغطي هذه الأراضي مساحة 709 كم²، أي مايعادل 7.1\% من جملة مساحة منطقة الدراسة، وتثغل السهل الفيضي و المناطق المجاورة له، وهى مستغلة تماما فى لهى لهاري

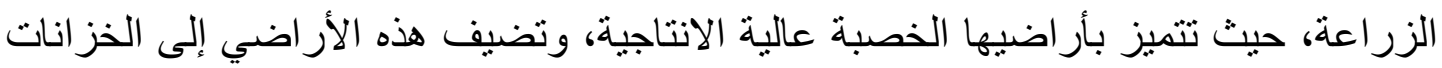
الجوفية كميات وفيرة من المياه من خلال المياه المنسرب من عملية الري.

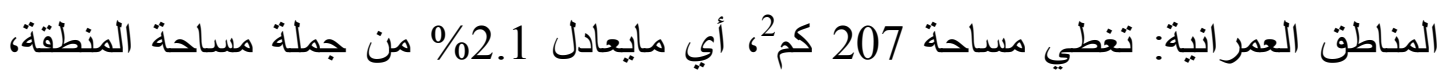
وتعاني معظم هذه المناطق من الحرمان من الصرف الصحي، والصرف بها عبارة عن بيارات في باطن الأرض، كما تعاني المناطق التي تخدمها شبكة صرف من من التهاللك مما يؤدي إلى زيادة

$$
\text { عمليات التسرب منها. }
$$

> أراضي السهول الرسوبية: نغطي هذه الأر اضي سهل الجلابة و المنطقة المعندة شرق سهل كوم أمبو، وتغطي مساحة 2171.1 كم²، أي مايعادل 21.6\% من جملة مساحة منطقة الدراسة. أراضي قبعان الأودية: نغطي مساحة 252.8 كم2، أي مايعادل 2.55\% من من من مساحة منطقة الدراسة، وتتحدر إلى منطقة الدراسة العديد من الأودية سواء من الهضبة الثرقية أو الغربية، وتضيف هذه الأودية كميات هائلة من المياه إلى الخزانات الجوفية في حالة تساقط السيول عليها. الأر اضي الصخرية: تتمثل فى البيدمينت و الهضاب و التلال المنعزلة، وهي مناطق غير صالحة للزر اعة، فتربة هذه المناطق ضحلة القطاع، و غالبا ما تكون صخرية وتغطى فى بعض المو اقع لهابع بطبقة رقيقة من الحصى أو الرمال، وتغطي هذه الأراضي مساحة 6607.5 كم، أي مايعادل 65.9\% من جملة مساحة منطقة الدر اسة.

وقد تم إعطاء أهمية لكل استخدام من استخدمات الأر اضي وذللك طبقاً لتغذية الخز انات الجوفية، حيث تم إعطاء أهمية مرتفعة للمسطحات المائية، تليها المناطق الزر اعية حيث تضيف الزر اعات كميات وفيرة إلى الخزانات الجوفية وذلك من خلال عمليات الري، في حين تم إعطاء أهية منذفضة للمناطق الصحر اوية و القاحلة و الصخرية على التو الي.

شكل (9) أنماط استخدامات الأر اضي بمنطقة الدر اسة.

2. المعالجة داخل نظم المعلومات الجغرافية (GIS processing) 
تأتي مرحلة المعالجة بعدما تم تجميع الطبقات المختلفة داخل قاعدة نظم المعلومات الجغر افية، حيث

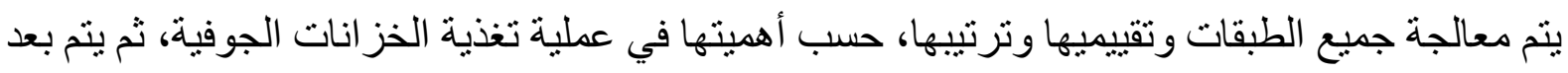

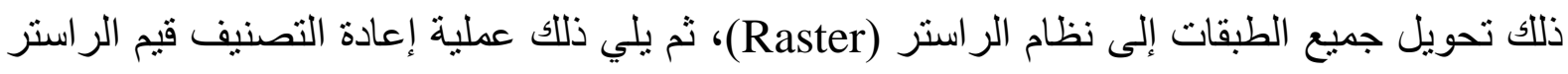
(Reclassification process) و وهي عبارة عن إعادة تصنيف قيم الراستر (Raster) وترتيبها وتوحيدها، و إعطائها قيم بسيطة تسهل عملية معالجتها، ويتم في هذه العملية ترتيب أهمية المناطق طبة إنقاً

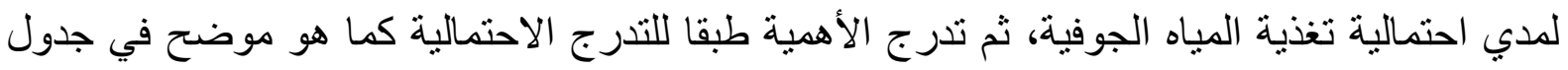
(1)، وفي هذه المرحلة تم إعادة تصنيف جميع الطبقات المستخذمة بالنموذج. 
جدول (1) وزن و أهمية كل طبقة من طبقات النموذج بناءاً على تغذية الخزانات الجوفية.

\begin{tabular}{|c|c|c|c|c|}
\hline وزن الطبقة & التصنيف الجياه & Rank & التصنيف & 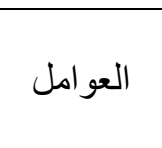 \\
\hline \multirow{6}{*}{25} & جيدةً جداً & 6 & نهر النيل، رواسب نيلية حديثة، & \multirow{6}{*}{ جيولوجية } \\
\hline & جيدة جداً & 5 & رواسب الأودية، تكوين إدفو، بلايا & \\
\hline & متوسطة & 4 & تكوين الطارف، الحصي و الزلط & \\
\hline & ضعيفة & 3 & تكوين القصير ، أم برميل، أبو & \\
\hline & ضيفةً & 2 & تكوين تمساح، تيبس، طروان & \\
\hline & جداً جديفة & 1 & تكوين الضوي، الداخلة، كركر، & \\
\hline \multirow{6}{*}{20} & جيدةً جداً & 6 & 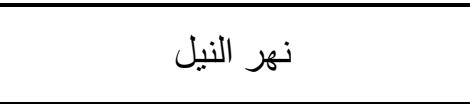 & \multirow{6}{*}{$\begin{array}{c}\text { الارتفاعات } \\
\text { الرقمية } \\
\text { (DEM) }\end{array}$} \\
\hline & جيدة جداً & 5 & السهل الفيضي & \\
\hline & متوسطة & 4 & السهول الرسوبية & \\
\hline & ضعيفة & 3 & الأودية ـ الكثبان الرملية & \\
\hline & ضديفة & 2 & البيدمينت_ـ البهاداـ مدرجات نهرية & \\
\hline & جداً جديفة & 1 & الجبال ـ الهضاب & \\
\hline \multirow{6}{*}{15} & جيدة جداً & 6 & انحدار ات خفيفة جداً & \multirow{6}{*}{$\begin{array}{l}\text { دالانحدار } \\
\text { (slope) }\end{array}$} \\
\hline & جيدة جداً & 5 & انحدار ات خفيفة & \\
\hline & منوسطة & 4 & انحدار ات منوسطة & \\
\hline & ضعيفة & 3 & انحدار ات شديدة & \\
\hline & ضديفة & 2 & انحدار ات شديدة جداً & \\
\hline & جداً جداً & 1 & انحدار ات شديدة الخطورة & \\
\hline
\end{tabular}

المصدر : من عمل الطالب بالاعتماد على الدر اسات السابقة ونموذج نظم المعلومات الجغر افية.

3. معالجة النتائج ومعايرتها:

بعد تشغيل النموذج (Model) ينتج عنه خريطة شكل (10) توضح توزيع معدلات تغذية الخز انات الجوفية بمنطقة الدر اسة، ويتبين من در استها أن هناك اتفاق بين طبيعة منطقة الدر اسة وتوزيع معدلات التغذية بالمنطقة، حيث يتبين أن معدلات التغذية تزداد بالقرب من نهر النيل، بمناطق السهل الفيضي حيث 
تصل إلى أعلي معدلاتها، حيث الزراعة الكثيفة، وارتفاع كثافة كلاً من شبكة الترع و المصارف و المناطق العمر انية، كمايضاف إلى ذللك اتجاه ميل الطبقات في اتجاه نهر النيل، وبالتالي ارتفاع التغذية التهنه من مناطق الاستصلاح الزراعي على أطراف السهل في اتجاه السهل الفيضي بالقرب من نهر النيل، النهاه وتغطي هذه المناطق مساحة 370.7 كم²، أي مايعادل 3.7\% من جملة مساحة المنطقة شكل (11). كما تزداد معدلات التغذية في المناطق المجاورة للسهل الفيضي للنيل، ولكن بمعدلات أقل منه، حيث

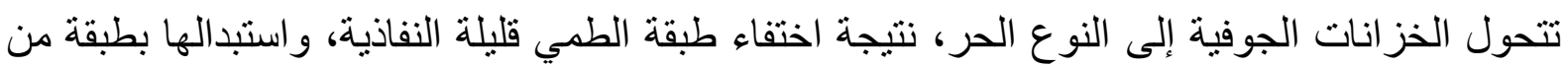
رواسب الأودية، والتي تتميز بنفاذيتها العالية، كما أن هذه المناطق تشغلها مساحات واسعة من الأراضي

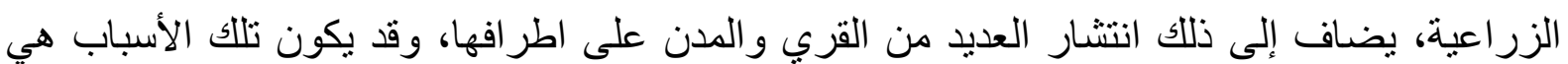
المسئولة عن ارتفاع تغذية تلك المناطق. بصن.

في حين تأني مناطق السهول الرسوبية سواء بمنطقة سهل الجلابة أو في المنطقة الممتدة شرق سهل

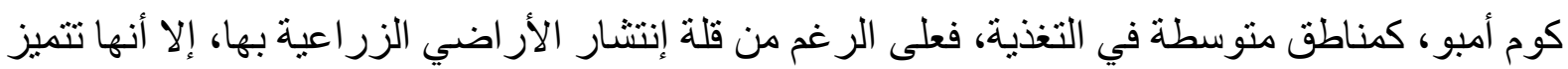

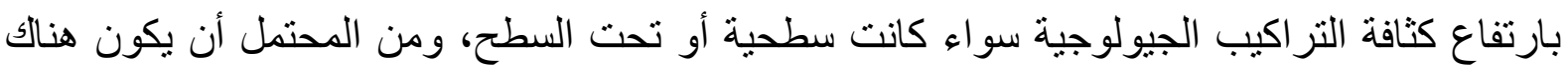
تغذية تصل لتلك المناطق من نهر النيل، نظر اً لقربها الثديد منه، وتغطي هذه المناطق مساحة 2790.5 كم2، أي مايعادل 27.8\% من جملة مساحة المنطقة.

في حين تأتي مناطق الهضاب كأقل مناطق من حيث معدلات التغذية، وتغطي مساحة 5744 كم²،

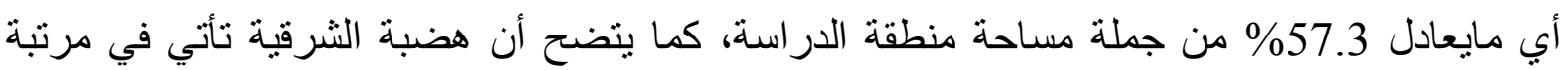

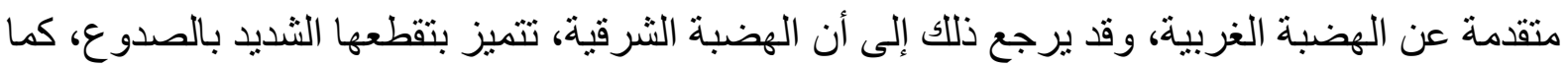
يضاف إلى ذلك طبيعة تكويناتها الصخرية، حيث تتكون من الحجر الرملي النوبي. في حين تمثل هضبة سن الكداب أقل مناطق التغذية، حيث الارتفاعات الثناهقة، والانحدارات الثديدة، يضاف إلى ذلك طبيعة تكويناتها الصخرية.

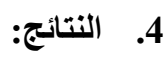

بناءاً على توزيع معدلات التغذية بمنطقة الدراسة، يتبين أن معدلات التغذية ترتفع بالمناطق القريب من نهر النيل، وهي بذلك تمثل أهم مناطق الخزانات الجوفية حيث تتميز باستدامة مياهها، كما تتميز بجودة مياهها، لذلك من المكن أضافة آبار جديدة للمياه الجوفية، أما بالبعد عن نهر النيل فتقل معدلات التغذية لذا لابد أن يكون هناك دراسات تفصيلية عن كميات المياه المتاحة في هذه المناطق، ومعدلات التغذية والسحب الأمن من هذه المباه، وذلك للمحافظة على هذا المصدر الهام للمياه العذبة من النفاذ و التدهور نتيجة السحب الجائر. 
(1)محمد خميس الزوكة، (1998): "جغر افية المياه"، دار المعرفة الجامعية الاسكندرية، ص 268.

(2) Shaban A, Khawlie M, Abdallah C., (2006): "Use of remote sensing and GIS to determine recharge potential zones: the case of Occidental Lebanon", Hydrogeol J., 2006; 14:433-43.

(3) El-Baz F., Himida I., (1995): "Groundwater Potential of the Sinai Peninsula, Egypt. Cairo, Egypt”, US Agency for International Development.

(4) GHONEIM E., El-Baz F., (2007): "DEM-optical-radar data integration for palaeohydrological mapping in the northern Darfur, Sudan: implication for groundwater exploration”, International J. of R.S., Vol. 28, No. 22, P. 50015018.

(5) Al Saud M., (2010): "Mapping potential areas for groundwater storage in Wadi Aurnah Basin, western Arabian Peninsula, using remote sensing and geographic information system techniques". Hydrogel J., 18:1481-95.

(6)El Fayoumy, J., (1968): "Geology of groundwater supplies in the region east of the Nile Delta", Unpublished Ph. D. Thesis, Fac. of Sci., Cairo Univ., Geology Department, Cairo.

(7)Lattman L. H., Parizek R. R., (1964): "Relationship between fracture traces and the occurrence of groundwater in carbonate rocks". J Hydro, 2: 73-91.

(8)Edet A.E., Okereke C.S., Teme S.C., Esu E.O., (1998): “Application of remote sensing data to groundwater exploration: a case study of the Cross River State, southeastern Nigeria”, Hydrogel J. 6:394-404 